\title{
Governança da água na Região Metropolitana de São Paulo - desafios à luz das mudanças climáticas
}

\author{
PEDRO ROBERTO JACOBI, I MARCOS BUCKERIDGE II \\ e WAGNER COSTA RIBEIRO III
}

\section{Introdução}

$\mathrm{F}$ ORNECER água para mais de 20 milhões de habitantes é um enorme desafio. Agregue-se a ele a oferta de água para a intensa atividade industrial e para a residual, mas ainda presente, agricultura. Como resultado, tem-se um quadro de estresse hídrico que perdura há décadas e que enfrenta, a intervalos menores, períodos de escassez aguda de água. A situação geográfica da Região Metropolitana de São Paulo (RMSP) também dificulta o acúmulo de água. Trata-se de uma bacia encravada em áreas mais elevadas que, apesar de verterem água para o Rio Tietê, o principal a cortar essa porção do território paulista, o fazem em volume reduzido ao atravessar a região metropolitana, por fatores como o desmatamento intenso, a urbanização acelerada e o gradiente do rio, que é muito reduzido, o que faz que a água do Rio Tietê que passa pela RMSP, em especial no município de São Paulo, tenha uma velocidade reduzida.

Por isso o sistema de captação, tratamento e distribuição da água envolve diversas bacias, parte delas localizadas em outras unidades da federação, como Minas Gerais e Rio de Janeiro, o que remete o abastecimento de água para uma escala federal, com as implicações políticas decorrentes desse fato. Além disso, a maioria dos 39 municípios que a integram a RMSP delegou o serviço de abastecimento de água e coleta e tratamento de esgoto a uma empresa que era pública, mas que passou a operar na perspectiva do mercado ao abrir seu capital em bolsas internacionais. Como resultado, a água tornou-se uma mercadoria rara e escassa.

Crises sazonais, que ocorrem a pelo menos cada dez anos, embora tenham sido registradas em intervalos menores nos últimos anos, demonstram, porém, a fragilidade hídrica da RMSP.

Do ponto de vista hídrico, a RMSP funciona como um sistema complexo e integrado (Buckeridge; Ribeiro 2018) (Figura 1), de tal forma que um período de escassez de chuva que diminua o suprimento de água afeta perigosamente o sistema como um todo. 


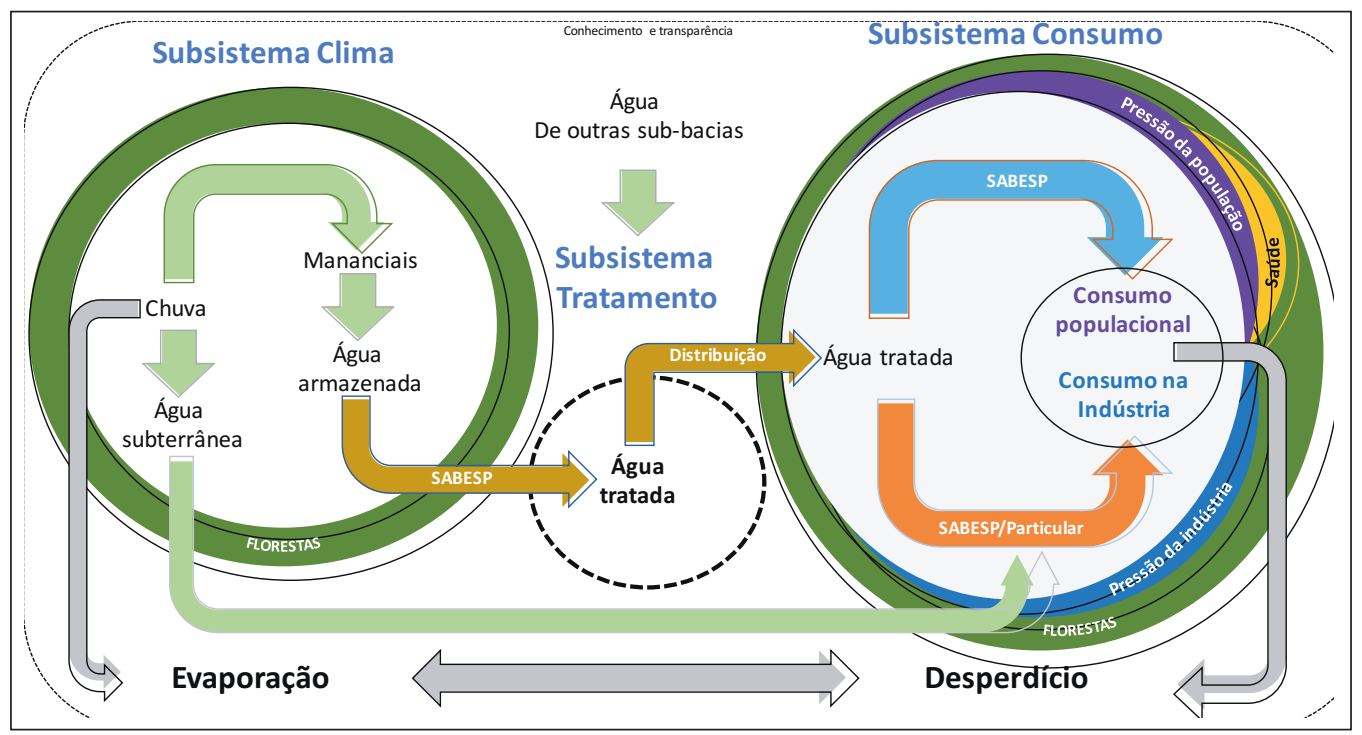

Fonte: Buckeridge e Ribeiro (2018, p.20).

Figura 1 - Origens, consequências e perspectivas sobre a crise da água na RMSP.

Na RMSP, a água é armazenada em um conjunto de mananciais que incluem reservatórios (p. ex. Billings, Cantareira e reservatórios subterrâneos). Para que possamos considerar um evento agudo de escassez de água como crise hídrica, é necessário que o sistema hídrico passe por um período de grande proximidade entre demanda e suprimento de água. Como mostrado na Figura 1, há diversos pontos que podem fortalecer a resiliência do sistema, notadamente a diminuição do desperdício e o aumento de eficiência do uso da água pela indústria e pela agricultura na RMSP. Outro elemento de grande importância é o conjunto de florestas periurbanas que ainda persiste na RMSP. Essas florestas oferecem uma importante proteção dos mananciais, sem os quais a região poderia entrar em colapso permanente. As florestas periurbanas não somente protegem física e biologicamente os mananciais, mas são também capazes de produzir grande quantidade de vapor de água. Buckeridge (2015) calculou que somente os $79 \mathrm{~km}$ quadrados de área da Cantareira seriam capazes de produzir uma "vazão" evapotranspiratória equivalente a 25 vezes a do Rio Tietê. Os valores integrados das árvores dos demais municípios da RMSP e das florestas periurbanas ainda precisam ser calculados, mas podemos estimar que tais valores serão muito significativos no sistema hídrico da RMSP. Essas estimativas apontam claramente para uma necessidade absoluta de preservar as florestas periurbanas e intensificar a arborização viária na RMSP.

Além dos fatores intrínsecos inerentes ao funcionamento sistêmico do balanço hídrico da RMSP, há fatores externos que poderão afetar a região por décadas. Tais fatores se relacionam com o avanço dos impactos das Mudanças Climáticas Globais (Ribeiro, 2008; Di Giulio et al., 2017; Di Giulio et al., 2018; Buckeridge et al., 2019). 
A complexidade do sistema hídrico da RMSP precisará de uma atenção especial. Isso significa que poderemos ter, em certos momentos, excesso de água, mas também outros eventos de seca similares ao que São Paulo experimentou na crise hídrica de 2013-2015. Os efeitos sobre as regiões urbanas poderão oscilar entre extremos mais amplos do que conhecemos até agora, afetando, em geral de forma negativa, a disponibilidade de água para as populações urbanas (Escobar, 2020).

Dadas a complexidade da governança da água na RMSP e a iminência de efeitos cada vez mais fortes das mudanças climáticas, a região precisa se preparar para evitar, ou minimizar, as consequências relacionadas à saúde e a vida dos habitantes, bem como os possíveis prejuízos econômicos que poderão ocorrer.

Esse conjunto de temas será abordado neste artigo, que tem como objetivo discutir como os efeitos das mudanças climáticas podem afetar o sistema de governança da água na RMSP. Para alcançar esse objetivo, a estratégia usada é a compilação da literatura sobre temas como o processo de urbanização acelerada no Brasil e suas implicações, a governança da água no Brasil e em especial na RMSP e sobre as mudanças climáticas e seus efeitos sobre áreas de elevada densidade populacional. O texto aborda aspectos da governança da água no estado de São Paulo, a crise hídrica na RMSP 2013/2015; os componentes da crise de governança, e o papel da sociedade civil, num contexto de mudanças climáticas.

\section{Governança da água em São Paulo}

No final da década de 1970, técnicos ligados à gestão dos recursos hídricos iniciaram uma reflexão sobre o sistema de gestão da água no estado de São Paulo. As transformações ocorridas no sistema de gestão tiveram início dos anos 1990, quando a gestão passou para o modelo descentralizado, participativo e integrado e quando foi aprovada a legislação estadual de gestão de recursos hídricos (Jacobi, 2009).

O sistema migrou de um modelo centralizado pelo estado para o ideário de descentralização e integração, e adotou o recorte da bacia hidrográfica como unidade de gestão, o que resultou em 22 Unidades Hidrográficas de Gerenciamento de Recursos Hídricos do Estado de São Paulo (UGRHI). Ainda assim, o governo do estado de São Paulo tem forte presença na gestão, mesmo nas instâncias deliberativas nas quais pressupõe-se maior participação de atores externos ao aparato estatal.

Ao abordar o tema da governança da água é preciso considerar o arranjo político, social, econômico e administrativo para desenvolver e gerir os recursos hídricos e os serviços de abastecimento de água para os diferentes segmentos da sociedade. Essa requer um ambiente colaborativo, capaz de estimular e facilitar iniciativas entre os setores público e privado, e o envolvimento de diferentes atores sociais, além da necessidade de equilibrar o processo da gestão, face à diversidade de interesses, e como mecanismo de controle social, frente à possibilidade de os processos de tomada de decisão não contemplarem os diversos interesses em questão (Jacobi, 2009). 
Para que os processos de governança da água possam se concretizar, são necessárias condições, como inclusão, accountability, participação, transparência, previsibilidade e capacidade de resposta (Ribeiro, 2009), e garantir que os processos decisórios sejam sempre embasados no conhecimento científico.

Pahl-Wostl et al. (2012) pontuam que experiências de gestão dos recursos hídricos têm mostrado que o compartilhamento das responsabilidades e estruturas de coordenação vêm alcançando bons resultados. Isso parece também estar ocorrendo em relação aos desafios relacionados às mudanças climáticas, que têm tido melhores respostas com experiências de governança policêntrica. A busca recente de mecanismos capazes de estabelecer um novo quadro para a gestão dos recursos hídricos tem encontrado como principal desafio a necessidade de alterar a escala da gestão, no sentido de ir além dos limites antes estabelecidos pela divisão política. Com a crescente demanda de recursos hídricos, será cada vez mais necessária a transposição de água entre bacias, o que implica decisões políticas que afetam a oferta de água em cada unidade de gestão. Outro desafio é a institucionalização da participação de diferentes atores sociais (Pahl-Wostl et al., 2012). As transposições entre bacias têm boa base em engenharia, mas a base científica utilizada pelo governo é geralmente deficiente em relação a pontos importantes, como os impactos ambientais e sociais relacionados.

\section{A crise hídrica de 2013/2015 na RMSP}

Desde 2012, diferentes municípios do Brasil se depararam com reduções da pluviosidade, delineando um cenário complexo de escassez hídrica. Este fenômeno climático causou impactos graves na oferta de água para o abastecimento público e outros usos, como irrigação e geração de energia elétrica (ANA, 2014).

As chuvas abaixo da média contribuíram para o agravamento da deficiência de oferta de água por bacias hidrográficas caracterizadas como críticas, devido à baixa disponibilidade hídrica qualitativa e/ou quantitativa. A Agência Nacional de Águas (ANA) destaca que a RMSP apresenta maior vulnerabilidade hídrica, caracterizada pela baixa garantia dos mananciais atualmente explorados (ANA, 2014).

Estudos climatológicos relacionam os fluxos de vapor de água produzidos pela evapotranspiração da floresta Amazônica com a incidência de chuvas nas regiões Centro-Oeste, Sudeste e Sul do Brasil (Nobre, 2010). Isso significa que o desmatamento no norte do Brasil é capaz de afetar diretamente o regime de chuvas na RMSP e que políticas públicas integradas são necessárias para controlar a situação.

No verão de 2014, ocorreram em diversas regiões do estado de São Paulo secas combinadas com altas temperaturas que ultrapassaram diversos recordes. Ao final da estação chuvosa vários reservatórios responsáveis pelo abastecimento de água para a população do estado atingiram níveis mínimos críticos, em particular o sistema Cantareira, o principal fornecedor de água para a RMSP, que na época abastecia mais de 8 milhões de pessoas (Ambrizzi; Coelho, 2018). 
Conforme mostrado na Figura 2, em relação à climatologia, os meses de dezembro de 2013 a fevereiro de 2014 apresentaram, para a região sudeste do estado de São Paulo, que inclui a RMSP, déficits de precipitação da ordem de $95,5,264,7$ e $219,3 \mathrm{~mm}$, respectivamente. No verão seguinte, dezembro de 2014 e janeiro de 2015 apresentaram déficits similares aos de dezembro de 2013 e janeiro de 2014, porém em fevereiro e março de 2015 os valores observados se aproximaram da média climatológica. A comparação entre os dois fenômenos mostra que há uma "janela" de vulnerabilidade em que, se não houver precipitação suficiente, se conecta com uma diminuição rápida nos níveis dos mananciais devido ao consumo alto durante o verão na RMSP.

Além da alteração climática associada ao desmatamento na região Norte do país, é preciso considerar também a ocupação intensa nas áreas de proteção aos mananciais da RMSP. As áreas de proteção e recuperação de mananciais são efetivamente ou potencialmente utilizadas para o abastecimento público, conforme disposto na Lei do Estado de São Paulo n.9.866/1997 (São Paulo, 1997i), que estabelece os critérios de uso do solo nessas regiões.

A degradação das áreas de mananciais, criadas justamente para evitar a degradação da água usada para abastecer a população, está associada à concentração da renda que expulsa a população mais pobre e vulnerável para as áreas periféricas, e às políticas habitacionais insuficientes às demandas (Maricato et al., 2010). Diversas notícias em jornais publicadas recentemente ( $O$ Estado de $S$. Paulo, 24 de junho de 2019) mostram que as invasões de terra nessas regiões estão cada vez mais associadas com ações do crime organizado, o que configura uma realidade muito preocupante quanto ao uso e ocupação do solo em regiões críticas do entorno da cidade de São Paulo.

Parece haver, portanto, uma forte conexão entre a desigualdade do ponto de vista de uma ética socioambiental com valores instrumentais (Buckeridge et al., 2019). Além disso, a diminuição da desigualdade na RMSP seria um fator crucial para adaptá-la às possíveis crises hídricas originadas por eventos extremos atrelados às Mudanças Climáticas Globais. Por outro lado, como o consumo de água é desigual no município de São Paulo (Ribeiro, 2011), a diminuição da desigualdade teria potencial de aumentar a demanda de água para abastecimento populacional, o que deveria levar a uma revisão do consumo da água por outros usos, como o industrial. Portanto, o esforço em melhorar a adaptabilidade da RMSP aos impactos das mudanças climáticas passa por ações sistêmicas, nas quais vários fatores têm que ser alterados ao mesmo tempo de forma cuidadosa e planejada.

A RMSP com seus mais de 20 milhões de habitantes e 39 municípios é abastecida por oito sistemas produtores de água, operados pela Companhia de Saneamento Básico do Estado de São Paulo (Sabesp). Dentre os sistemas produtores de água, destacam-se o sistema Cantareira, o sistema Guarapiranga e o sistema Alto Tietê (ANA, 2010) que, em conjunto, atendem mais de $80 \%$ da 
(c)

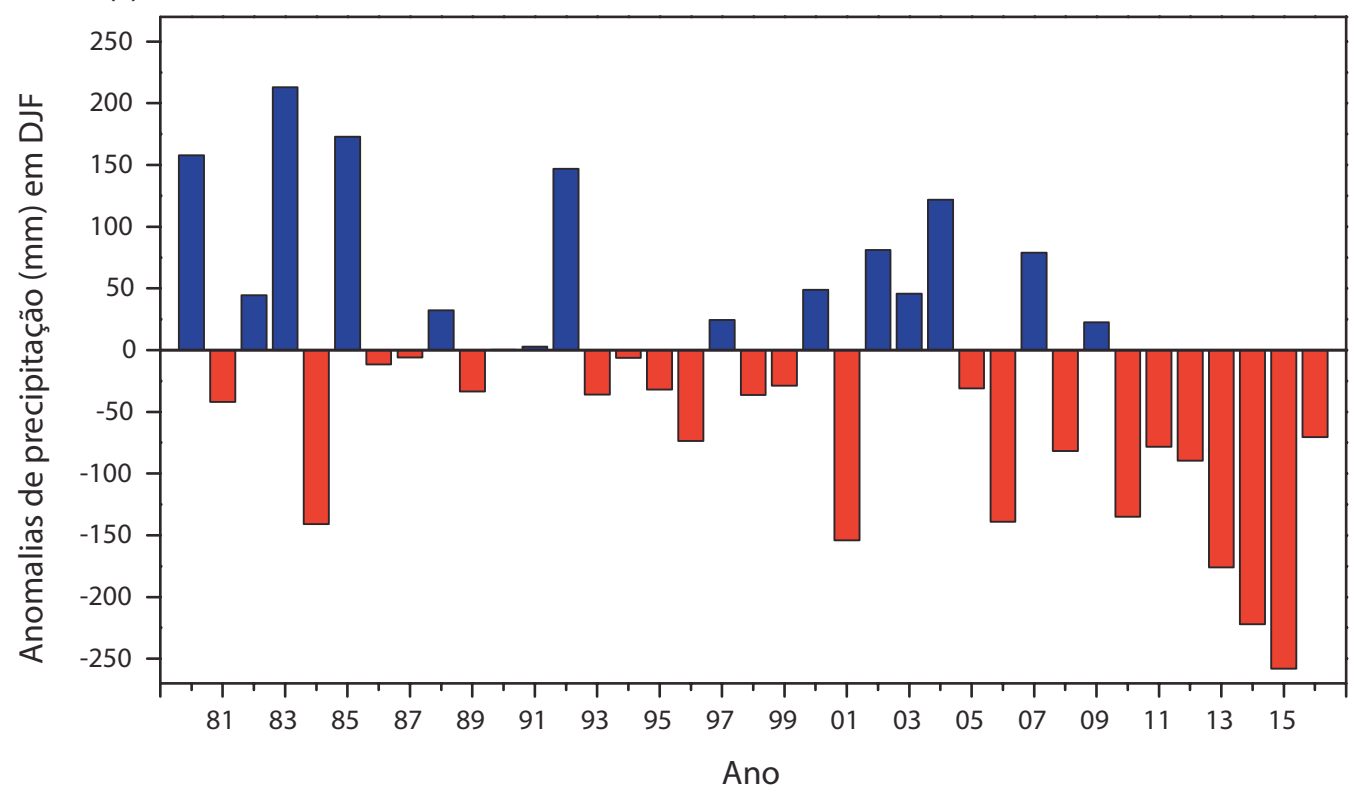

Fonte: Ambrizzi e Coelho (2018, p.25).

Figura 2 - Série temporal de anomalias de precipitação para o verão (DJF) de $1979 / 1980$ a $2014 / 201$.

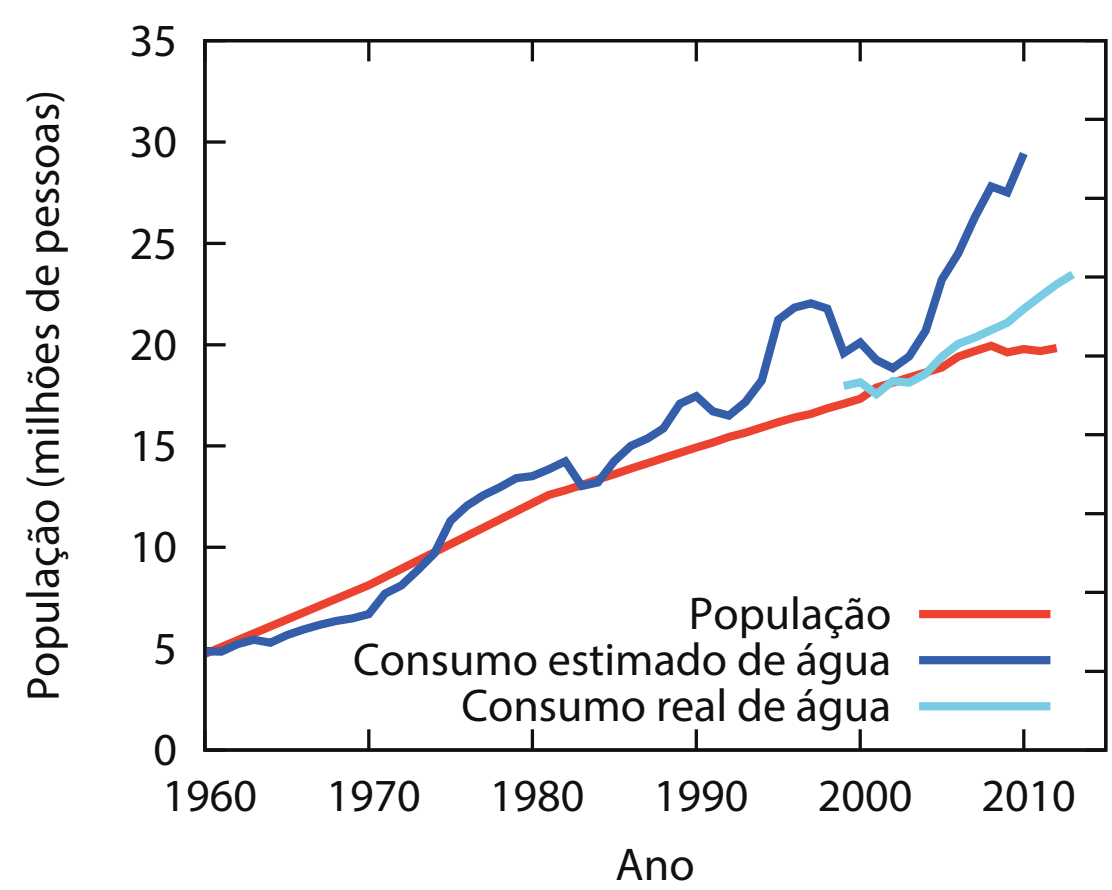

1800

1600

1400

1200

กับ

Fonte: Ambrizzi e Coelho (2018, p.30).

Figura 3 - População e consumo da água na RMSP. 
população. O sistema Cantareira, principal sistema de abastecimento da RMSP, era responsável, até a crise hídrica de 2013-2015, por abastecer mais de oito milhões de pessoas (Chiodi et al., 2013), com $31 \mathrm{~m}^{3} / \mathrm{s}$ sendo $24,8 \mathrm{~m}^{3} / \mathrm{s}$ para atender o consumo da população. Em 2020 o sistema Cantareira é responsável pelo atendimento de 5,6 milhões de pessoas o que representa uma redução de 30\%.

A bacia do Alto Tietê dispõe de oferta de água per capita considerada baixa, com 130,68 $\mathrm{m}^{3}$ /ano por habitante, devido à sua reduzida área geográfica, elevada concentração populacional e de indústrias (PBHAT, 2016).

Os aumentos do consumo de água e da população foram muito provavelmente os principais fatores associados à crise hídrica sistêmica que a região vem experimentando. A Figura 3 mostra a variação ao longo do tempo do consumo de água (estimado e atual) e da população da RMSP. Essa figura ilustra que a taxa de aumento de consumo de água vem superando a taxa de crescimento da população, e ambos mostram uma forte tendência de crescimento ao longo dos anos. Esse resultado é enfatizado ainda mais pela Figura 4, que mostra a tendência da estimativa do consumo de água entre os anos 1960-2010. Grande parte do estado de São Paulo e de outras áreas do Sudeste indicam uma tendência positiva, mostrando que o consumo de água vem aumentando sistematicamente (Ambrizzi; Coelho 2018).

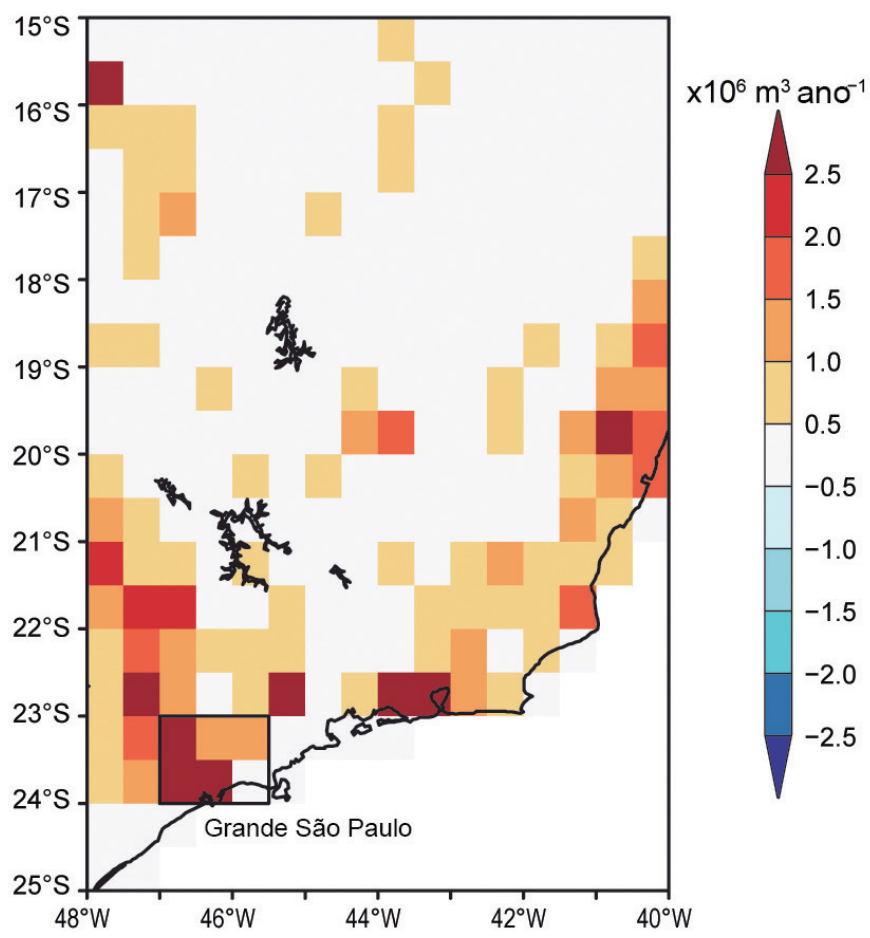

Fonte: Ambrizzi e Coelho (2018, p.31).

Figura 4 - Tendência temporal da estimativa do consumo de água no período 19602010. 
$\mathrm{Na}$ área do Comitê do Alto Tietê, o déficit de saneamento está ainda associado, segundo a ANA (2014), com a necessidade de expansão da rede coletora, complementação das interligações dos coletores tronco e interceptores e eliminação das ligações clandestinas nos sistemas de drenagem de águas pluviais. Dados do Plano da Bacia Hidrográfica do Alto Tietê (2016) mostram que, em $2015,88,8 \%$ do esgoto era coletado, $53,4 \%$ tratado, e que, portanto, a eficiência do sistema de esgotamento seria de 48,1\%. Além disso, Ribeiro (2011) indicou que o uso da água é muito desigual na RMSP, sendo a atividade industrial grande usuária do recurso (FUSP, 2009).

Segundo o Plano da Bacia do Alto Tietê, $59 \%$ das outorgas de direito de uso da água são destinadas ao abastecimento público e lançamento de efluentes domésticos e 39\% são destinadas para uso industrial. A RMSP está inserida em uma área de insuficiente disponibilidade hídrica, em quantidade e qualidade, e de certa complexidade hidrológica, devido a obras de canalização, transposição e alteração de trechos de rios.

Apesar de contar com uma lei que implementa um sistema de gestão da água integrado, participativo e descentralizado, as ações coordenadas pelo governo do estado de São Paulo não têm sido capazes de evitar a grave ameaça de falta de água na RMSP. A frequência das estiagens pode ser constatada, posto que a RMSP enfrentou dificuldades nas décadas de 1980, 1990, 2000 e 2010. Portanto, os gestores públicos já possuem conhecimento de que as crises de falta de chuvas se repetem e podem vir a ocorrer novamente.

Cabe enfatizar que a questão da segurança hídrica (Jacobi et al., 2019) na RMSP estava na pauta dos principais meios de comunicação desde o início de 2014 , em razão da primavera e verão atípicos (entre 2013/2014), com pluviosidade abaixo da média histórica para o mesmo período e o verão de 2013 foi o mais quente desde 1943, quando começaram as medições, na medida em que a temperatura média ficou $3{ }^{\circ} \mathrm{C}$ acima da média (BBC, 2014).

$\mathrm{O}$ que antes era apenas um cenário pessimista, ao longo do ano foi se concretizando numa das piores crises que a população já vivenciou, decorrente do baixo nível pluviométrico em algumas das represas que abastecem a RMSP. Porém, cabe enfatizar que a crise hídrica foi acima de tudo reflexo da falta de planejamento estratégico que afeta o sistema de abastecimento da Região (Cortes, 2015).

Existia o desafio de manter o abastecimento de água para todos os usuários, inclusive os setores econômicos, enquanto os níveis de água nos principais reservatórios que abastecem a RMSP estavam abaixo do volume útil, com o uso do volume da reserva técnica, chamado de "volume morto". ${ }^{1}$ A mídia apontou como principal causa da pior crise hídrica da história da região, principalmente, a falta de chuvas no verão 2013/2015 nas cabeceiras dos rios que formam parte dos sistemas de abastecimento de água, como ponto de vulnerabilidade do sistema hídrico da RMSP (Jacobi et al., 2015). 
Mas apesar da pluviosidade abaixo da média, outras questões atreladas à crise hídrica contribuíram para a compreensão da grave situação que colocou em risco o desabastecimento da maior cidade do país e municípios vizinhos, mas que não fazem parte da história oficial sobre a crise que a RMSP enfrentou. Não se pode, de fato, desconsiderar a questão climática entre os motivos desse momento crítico, mas a crise hídrica de 2014 evidenciou problemas relacionados à gestão dos recursos hídricos e demonstrou a necessidade de estabelecer uma nova relação entre a gestão e o uso da água para garantir o consumo sustentável. Entre eles a crescente urbanização e o aumento da população, o que aumentou fortemente a demanda, a infraestrutura inadequada e a falta de articulação entre os diversos stakeholders para a solução das questões críticas (Buckeridge; Ribeiro, 2018).

Uma governança sistêmica ganha centralidade, pois implica a implementação de políticas públicas integradas que atendam às demandas sociais com a participação da sociedade, de forma que possam fortalecer a "gestão democrática, integrada e compartilhada" (Jacobi et al., 2012; Buckeridge; Ribeiro 2018).

Nessa perspectiva, ao se abordar a crise hídrica, é preciso relacionar a escassez de água ao desequilíbrio no acesso e a problemas no atual modelo de governança, assim como aos conflitos da disponibilidade que afetam principalmente a população mais carente (Arrojo, 2006). Cabe também destacar o quanto a falta de tratamento de esgoto doméstico, desmatamento e ocupação em áreas de mananciais, a falta de planejamento para a construção de novos reservatórios, a falta de investimentos para a redução de perdas de água no sistema de distribuição e a falta de coordenação institucional devem ser considerados dentre os fatores que acentuaram o impacto da crise hídrica.

Num contexto no qual mudanças climáticas avançam rapidamente, levando a um pico de impacto entre 2030 e 2050 (que estão condicionadas a conter, ou não, a elevação da temperatura a $1,5^{\circ} \mathrm{C}$ ), as estratégias de adaptação (Jacobi et al., 2019; Trimble; Mazzeo, 2019) devem estar sob controle do Estado e com a participação da sociedade como um todo (inclusive das empresas). Dessa forma, o sistema provavelmente apresentaria maior nível de "resiliência sistêmica", garantindo que possíveis efeitos de novas crises hídricas sejam minimizados nas próximas duas décadas.

Um dos pontos centrais da discussão sobre a crise vai em direção às responsabilidades das instituições governamentais em relação ao planejamento, transparência e informação.

A transparência também pode ser entendida como um instrumento dentro de um arcabouço de práticas com o intuito de avaliar o comprometimento dos atores sociais nos processos de tomada de decisão e ao mesmo tempo combater práticas de corrupção (Lavalle; Vera. 2010). Assim, transparência surge como um dos instrumentos para avaliar a efetividade, integralidade e legitimidade das novas práticas de governança na qual a participação é um fator chave nos processos democráticos. 
A fragilidade do sistema de governança do estado de São Paulo ficou evidente durante a crise hídrica de 2013 a 2015. Em que pese o fato de que amplas parcelas dos bairros periféricos da RMSP tiveram problemas com o abastecimento regular de água, o governo do estado de São Paulo buscou criar uma narrativa que negava a crise no sistema e a necessidade de racionamento (Jacobi et al., 2015). Apesar da negação, viveu-se uma verdadeira injustiça ambiental e espacial (Ribeiro, 2017), que foi constatada por órgãos de imprensa, que noticiaram a existência de contratos de demanda firme, um instrumento criado pela Sabesp que subsidia a água de grandes consumidores (indústrias, clubes esportivos, shopping-centres, entre outros), que pagam uma tarifa mais baixa desde que mantenham um consumo elevado. Para alguns críticos, essa foi uma das razões pela qual os gestores públicos não adotaram o rodízio de abastecimento, medida adotada em outras crises, mas que se revelam impopulares, sobretudo em anos de eleição, como foi o caso em 2014.

O crescimento da população na região, demonstrado pela Figura 3, tem demandado ampliação da infraestrutura e consequentemente de investimentos na ampliação do sistema de abastecimento, com o aumento da capacidade das estações de tratamento, ou no desenvolvimento dos mananciais. Ao longo dos anos, tem ocorrido redução no volume de água per capita disponível nos mananciais para captação e no volume que as estações de tratamento de água têm capacidade de tratar, conforme se mostra na Figura 2. Observa-se, portanto, que o sistema trabalha acima de sua capacidade operacional durante vários dias ao longo dos últimos anos (Cortes et al., 2015).

O baixo nível de governança do sistema de gestão da água ficou evidente na medida em que, já na década de 1970, especialistas previam a crise que ocorreu em 2014 (Tuffani, 2014). Em 2004, o Departamento de Águas e Energia Elétrica do Estado de São Paulo (DAEE) recomendou um conjunto de ações visando o aumento da disponibilidade de água para o abastecimento de água no município de São Paulo e menor dependência da importação de água da Bacia Hidrográfica do Rio Piracicaba, que envolve os rios Capivari e Jundiaí. No âmbito do debate relacionado ao contexto da crise constatou-se que a Sabesp, entre os anos 2008 e 2013 , não realizou os investimentos previstos em obras e ações para aumentar a oferta de água.

As constantes negativas do governo do estado de São Paulo em relação à gravidade da crise dificultaram o envolvimento da sociedade no enfrentamento dessa crise. Isso serviu como justificativa para que as iniciativas vindas da sociedade civil e dos comitês de bacia não fossem levadas em consideração. Para Jacobi et al. (2015), durante a crise, a falta de transparência foi uma constante no comportamento das instâncias de gestão do sistema de gestão da água no estado de São Paulo. Mesmo o processo de tomada de decisão a respeito das obras emergenciais adotadas foi feito sem a devida interlocução com os comitês de bacia envolvidos, motivando uma situação de conflito, inclusive com o esta- 
do do Rio de Janeiro, uma vez que parte das soluções envolviam o Rio Paraíba do Sul, uma bacia hidrográfica localizada nos estados de Minas Gerais, Rio de Janeiro e São Paulo.

A crise hídrica na RMSP de 2013-2015 tem raízes complexas, que emanam da gestão anacrônica do governo do estado de São Paulo por meio da empresa concessionária dos serviços de água, falta de transparência, ausência de visão sistêmica e do uso integral de dados científicos que pudessem ter provido a sociedade com uma visão transdisciplinar do problema (uma crise anunciada) de maneira a amenizar os impactos sobre a população, em especial aquela das periferias, que são as que dispõem de infraestrutura deficiente (quando existem). O que se deve alertar é que, com o avanço das mudanças climáticas globais, as previsões de aumento de eventos extremos é fato inexorável. Escobar (2020) discute o conceito de "roleta russa" de eventos climáticos com potencial catastrófico na região sudeste do Brasil. Em outras palavras, sabemos que o evento vai ocorrer, mas não podemos precisar onde exatamente ocorrerá. Torna-se, portanto, altamente provável que episódios de crise hídrica como o ocorrido em 2013-2015 se repitam no futuro. Por isso, sugerimos que uma abordagem sistêmica seja adotada imediatamente - não somente na RMSP, mas nas demais regiões metropolitanas do Sudeste - com vistas a diminuir ao máximo os impactos esperados.

\section{Crise de governança}

Em sistemas urbanos complexos, alguns dos desafios que a gestão da água enfrenta incluem os interesses conflitantes entre os diferentes setores, a ausência de cooperação entre as organizações e especialistas, diferentes interpretações da gestão integrada da água, dinâmicas de poder e a falta de capacidade de intervenções (Buckeridge; Ribeiro 2018). Os desafios da governança da água envolvem a participação efetiva dos cidadãos e das partes interessadas, assim como a resolução de conflitos e desequilíbrios, de forma que possa garantir o fornecimento de serviços eficientes e acessíveis, ou seja, de uma gestão sustentável dos recursos hídricos (Olsson; Head, 2015).

A complexidade que envolve a solução para a gestão da água no estado de São Paulo, e na RMSP em especial, necessita de um novo modelo de governança. Tal modelo tem que ser embasado em uma gestão sistêmica. Deve garantir tanto eficiência como efetividade, com a participação da sociedade nas ações e intervenções diante dos problemas e possíveis soluções. A dificuldade para implementação das políticas públicas ambientais contrasta com os avançados instrumentos legais. Portanto, é necessário pensar uma política de longo prazo, com transparência de informações, que atenda às necessidades da população e permita a participação da sociedade civil nas decisões e responsabilidades que terão impacto direto em suas vidas. É sobretudo importante que quaisquer decisões sejam obrigatoriamente embasadas em conhecimento científico (Buckeridge et al., 2019). 
O desafio que envolve quantidade e qualidade da água precisa equacionar problemas de acesso, assim como a regulamentação, o controle e a redução da demanda. Dessa forma, a governança deve abordar aspectos relacionados à tecnologia e ao comportamento em um modelo que possa incluir: segurança hídrica, água como bem comum, governança participativa, capacidade preditiva e monitoramento (Tundisi; Tundisi, 2015). Além disso, é preciso "avaliar a pertinência em manter indústrias intensivas no uso da água na RMSP; estimular o reuso da água; aumentar o tratamento de esgoto, que ao fim libera água para usos secundários, como o industrial" (Ribeiro, 2011, p.130-1). Nesse sentido, a participação e a mobilização da sociedade são primordiais para alcançar a sustentabilidade do sistema hídrico e ambiental. Outra questão que envolve a governança é a abordagem da água enquanto recurso que a reduz a uma mercadoria, e que contradiz a lógica de direito humano à água e ao saneamento, como preconiza a Organização das Nações Unidas (ONU).

Enfim, a água deve ser vista como um recurso diretamente relacionado à sustentabilidade da sociedade que habita o ambiente urbano. Sua gestão tem de ser feita de forma sistêmica de maneira a maximizar a sustentabilidade.

\section{Sociedade civil, mobilização e desafios}

A proposta do modelo estabelecido pela Política Estadual de Recursos Hídricos (PERH), na década de 1990, instituiu uma nova ordem para a gestão da água no estado de São Paulo, que rompeu com a tecnocracia e centralização. Porém, a inclusão dos novos atores sociais e os conflitos relacionados às diferentes demandas promovem disputa e negociação, por confrontar a tecnocracia e incluir atores da área ambiental, representantes municipais, da sociedade civil e de movimentos sociais, assim como as ONG e Universidades (Jacobi et al., 2015).

Diante da crise, em 2014 e 2015, entre as medidas adotadas pelo governo paulista destacaram-se a utilização da "reserva técnica" e as obras de interligação entre reservatórios, a diminuição da pressão em parte expressiva do dia (o que pode gerar contaminação da água e acarretar problemas de saúde), assim como a multa pelo consumo excessivo e o bônus para a economia de água. Diante desse cenário, ao se observar a sociedade civil e sua participação, verificou-se a emergência de algumas iniciativas, como a Aliança pela Água e o Coletivo de Luta pela Água, que demonstraram a capacidade de articulação de múltiplos atores diante do paradigma da escassez e da construção de uma nova cultura da água (Arrojo, 2006).

Esses representantes da sociedade civil enfatizaram, também, a necessidade de promover uma transição do modelo de gestão atual que envolvesse a direção das políticas públicas e a governança em cinco áreas: cuidar das fontes de água em áreas rurais e urbanas; diminuir desperdício e perdas de água; tratar e reutilizar a água sempre que possível; rever instrumentos econômicos, como tarifas de serviços de saneamento e outorga de uso dos recursos hídricos; e finalmente, ampliar participação e controle social (Jacobi et al., 2018). 
O processo de governança envolve múltiplas categorias de atores, instituições, inter-relações e temas, cada um dos quais suscetíveis a expressar arranjos específicos entre os interesses em jogo e possibilidades de negociação, expressando aspectos de interesse de coletividades, com ênfase na prevalência do bem comum, que seria a segurança hídrica da RMSP.

Um dos maiores desafios na governança da água é garantir uma abordagem aberta e transparente; inclusiva e comunicativa; coerente e integrativa; equitativa e ética (Jacobi, 2009). Para De Stefano et al. (2013), a participação pública permite que pessoas ou grupos de pessoas influenciem o resultado de decisões que vão afetá-las ou as interessa. Nesse sentido, a participação pública é amplamente considerada um fator que melhora a qualidade dos processos de governança da água.

Com um discurso técnico e centralizador, os dirigentes da época se omitiram quanto a um maior diálogo com a população, excluindo o envolvimento da sociedade na discussão, tanto da causa da crise, como também das possíveis soluções para o enfrentamento do problema.

Para que seja possível a participação pública nos processos de tomada de decisão torna-se necessário, porém, garantir a transparência e o acesso das informações para que os atores interessados possam se apropriar da problemática e então se engajar e cooperar em direção às ações de mitigação ou solução.

Além da disponibilidade e acesso, outra questão-chave relacionada à transparência das informações sobre a gestão da água, é que as informações devem ser adaptadas para que sejam compreendidas por diferentes públicos (De Stefano et al., 2013).

O cenário de escassez hídrica, reforçado pelas alterações climáticas, foi agravado pela incapacidade de comunicação e diálogo por parte do governo do estado de São Paulo sobre a gravidade da situação. A falta de propostas e de informações que contribuam para uma discussão profunda entre os diferentes usuários da água do Sistema Cantareira levou ao esgotamento da água do principal reservatório da região.

\section{Conclusões}

A crise da água, mesmo com os impactos negativos, demanda repensar senão o modelo atual de gestão da água, pelo menos a prática deste modelo. Por isso, é fundamental a adoção de uma nova estratégia de gestão integrada e participativa da água, que considere a sociedade como parte integrante da tomada de decisão.

Para Buckeridge e Ribeiro (2018), qualquer abordagem deve levar em consideração uma visão sistêmica de como os vários elementos do sistema hídrico de São Paulo se integram. Nesse sentido, a falta de pressão social pode ter sido fator importante para a demora na resposta pública, assim como a falta de um plano de contingência que deveria ter sido composto a partir das previsões ainda na década de 1970. 
Um dos pontos centrais da discussão sobre a crise deve ir em direção às responsabilidades das instituições governamentais em relação ao planejamento, transparência e informação, pilares centrais da participação cidadã. A percepção de que a crise hídrica é também um problema de gestão fica fortalecida diante do fato de que prevaleceu, por parte do governo do estado de São Paulo, uma postura de pouca transparência, um importante componente dos sistemas de gestão. Observa-se que este é um típico panorama de crise, na qual decisões rápidas têm que ser tomadas e há pouco tempo para consultas. Mas se quando uma crise se apresenta houver uma capacidade de antecipação, com planos de contingência que levem em consideração a gestão sistêmica, com consulta à sociedade, ela poderá ser enfrentada de forma mais eficiente pois, além das decisões em nível técnico, haverá participação efetiva da população, evitando consequências prejudiciais às pessoas.

No caso da crise hídrica de 2013-2015, a maneira como a sociedade foi informada não permitiu que se construísse uma narrativa que envolvesse os diferentes atores sociais e toda a sociedade no enfrentamento da situação.

Faz-se necessária, assim, a prática da governança enquanto um arranjo político e social capaz de apontar práticas e caminhos que podem contribuir com um ambiente de gestão mais transparente, no qual a participação social de um amplo conjunto de atores sociais interage em torno da busca conjunta de soluções para os problemas que afetam a todos. Um dos maiores desafios na governança da água é garantir uma abordagem aberta e transparente; inclusiva e comunicativa; coerente e integrativa; equitativa e ética.

As novas práticas de governança e a inclusão de atores sociais em novos espaços de negociação não só se tornaram chaves, mas também assumiram uma importância a ponto de servir como um fator de poder e influência sobre a tomada de decisão. Isto se deve ao fato de o sistema de governança ambiental ser composto pelo elemento político, que consiste em balancear os vários interesses e realidades políticas; mas também pelo fator credibilidade, com instrumentos que apoiem as políticas e possibilitem que as pessoas acreditem nelas.

Agradecimento - O autor Pedro Roberto Jacobi agradece o apoio da Fundação de Amparo à Pesquisa do Estado de São Paulo (Fapesp). O trabalho faz parte das atividades do Projeto Temático, em andamento, Governança ambiental da Macrometrópole Paulista, em face da variabilidade climática, processo n.2015-0304-9, financiado pela Fapesp e vinculado ao Programa Fapesp de Pesquisa sobre Mudanças Climáticas Globais. 
Notas

1 O chamado "volume morto" é uma reserva de água que não deve ser utilizada sob pena de inviabilizar o reservatório. Ele mantém uma cota de inundação da represa, o que protege o solo e evita seu ressecamento, como acabou ocorrendo na crise de $2013 / 2015$.

2 Resiliência possui diversos significados, mas neste texto está associada à capacidade de adaptação aos desafios que a gestão da água oferece. Ela deve ser sistêmica por considerar diversos aspectos que estão articulados, como as dimensões meteorológicas, climáticas, mas, principalmente, as de ordem política, social e econômica, com a participação dos diversos setores sociais envolvidos. Portanto, a resiliência sistêmica é a capacidade de adaptar-se a uma nova situação-problema considerando os diversos aspectos envolvidos na causa e mitigação do problema, envolvendo os agentes sociais afetados.

\section{Referências}

ANA. AGÊNCIA NACIONAL DE ÁGUAS. Conjuntura dos Recursos Hidricos no Brasil - Encarte Especial sobre a Crise Hidrica. 2014. Disponível em: <http://conjuntura. ana.gov.br/docs/crisehidrica.pdf>.

AMBRIZZI, T.; COELHO, C. A. S. A crise hídrica e a seca de 2014 e 2015 em São Paulo: Contribuições do clima e das atividades humanas. In: BUCKERIDGE, M.; RIBEIRO, W. C. Livro branco da água. A crise hídrica na Região Metropolitana de São Paulo em 2013-2015: Origens, impactos e soluções. São Paulo: Instituto de Estudos Avançados, 2018. p.22-35.

ARROJO, P. Los retos éticos de la nueva cultura del agua. Polis, Revista de la Universidad Bolivariana, v.5, n.14, 2006.

BBC. 2014. Disponível em: <http://www.bbc.com/portuguese/noticias/2015/05/ 150427_estiagem_sp_mv>. Acesso em: 10 jun. 2015.

BUCKERIDGE, M. Árvores urbanas em São Paulo: planejamento, economia e água. Estudos Avançados, v.29, p.85-101, 2015.

BUCKERIDGE, M. S.; PHILIPPI JUNIOR, A.; SILVA, R. Y. Combate às mudanças climáticas globais nas cidades. In: JACOBI, P. R.; TRANI, E. Planejando o Futuro Hoje: ODS 13, Adaptação e Mudanças Climáticas em São Paulo. São Paulo: IEE-USP, 2019. p.35-8. (ISBN 978-85-86923-58-6).

BUCKERIDGE, M. S.; RIBEIRO W. C. Uma visão sistêmica das origens, consequências e perspectivas das crises hídricas na região metropolitana de São Paulo. In: BUCKERIDGE, M.; RIBEIRO, W. C. Livro branco da água. A crise hídrica na Região Metropolitana de São Paulo em 2013-2015: Origens, impactos e soluções. São Paulo: Instituto de Estudos Avançados, 2018. p.14-21.

CHIODI, R. E. et al. Gestão dos recursos hídricos na área do Sistema Produtor de Água Cantareira: um olhar para o contexto rural. Ambiente e Água, v.8, n.3, p.151-65, 2013 .

CARloS, A. F. A. A condição espacial. São Paulo: Contexto, 2011.

CORTES, P. et al. Crise de abastecimento de água em São Paulo e falta de planejamento estratégico. Revista Estudos Avançados, v.29, n.84, maio-ago. 2015. 
DE STEFANO, 1. et al. Public participation and transparency in water management. In: DE STEFANO, L.; LLAMAS, R. (Org.) Water, agriculture and the environment in Spain: can we square the circle? Madrid: Taylor \& Francis, 2013.

DI GIULIO, G. M. et al. Mudanças climáticas, riscos e adaptação na megacidade de São Paulo, Brasil. Sustentabilidade em Debate, v.8, p.75, 2017. https://doi.org/10.18472/ SustDeb.v8n2.2017.19868

DI GIULIO, G. M. et al. Mainstreaming climate adaptation in the megacity of São Paulo, Brazil. Cities, v.72, p.237-44, 2018. <https://doi.org/10.1016/j.cities.2017.09.001>.

ESCOBAR, H. Mudança climática nas cidades: "Precisamos ficar preparados para o pior”. Jornal da USP. 2020. Disponível em: <https://jornal.usp.br/ciencias/ciencias-ambientais/mudanca-climatica-nas-cidades-precisamos-ficar-preparados-para-o- pior $/>$.

FUSP - FUNDAÇÃO DE APOIO À UNIVERSIDADE DE SÃO PAULO. Plano da Bacia Hidrográfica do Alto Tietê, São Paulo, 2009 (4v.).

JACOBI, P. R. Governança da Água no Brasil. In: RIBEIRO, W. C. (Org.) Governança da água no Brasil: Uma visão interdisciplinar. São Paulo: Annablume; Fapesp; CNPq, 2009.

JACOBI, P. R.; BUJAK, N. L.; SOUZA, A. do N. Pénurie hydrique et crise de gouvernance dans la Région métropolitaine de São Paulo. Brésil(s). Sciences humaines et sociales, Article 13, 2018.

JACOBI, P. R.; CIBIM, J.; SOUZA LEÃO, R. Crise hídrica na MMP e respostas da sociedade civil. Estudos Avançados, v.29, n.84, 2015.

JACOBI, P. R.; GÜNTER, W. M. R.; GIATTI, L. L. Agenda 21 e Governança. Estudos Avançados, v.26, n.74, p.331-9, 2012.

JACOBI, P. R.; TORRES, P. H. C.; GREESE, E. Governing Shallow Waters: SDG 6 and Water Security in Sao Paulo. In: Water Security and the Sustainable Development Goals. Global Water Security Issues (GWSI), Organized by Unesco i-WSSM. Case Studies. Daejeon, 2019.

LAVALLE, A.; VERA, G. Latina: tramas y nudos de la representación, la participación y el control social. México: Centro de Investigaciones y Estudios Superiores en Antropología Social - Universidad Veracruzana, 2010.

MARICATO, E. et. al. Crise urbana, produção do habitat e doença. In: SALDIVA, P. (Org.) Meio Ambiente e Saúde: o desafio das metrópoles. São Paulo: Instituto Saúde e Sustentabilidade, 2010. p.47-65.

NOBRE, C. A. et al. Vulnerabilidade das Megacidades Brasileiras às Mudanças Climáticas: Região Metropolitana de São Paulo, Sumário Executivo. São Paulo: Inpe/Unicamp/ USP/IPT/Unesp Rio Claro, 2010.

OLSSON, L.; HEAD B. W. Urban Water Governance in Times of Multiple Stressors: an editorial. Ecology and Society v.20, n.1, p.27, 2015.

PAHL-WOSTL, C. et al. From applying panaceas to mastering complexity: toward adaptive water governance in river basins. Environmental Science \& Policy, v.23, p.2434,2012 . 
PBHAT. Plano de Bacia do Alto Tietê. São Paulo: FABHAT, s. d.

RIBEIRO, W. C. Impactos das mudanças climáticas em cidades no Brasil. Parcerias Estratégicas (Impresso), v.27, p.297-321, 2008.

Impasses da governança da água no Brasil. In: RIBEIRO, W. C. (Org.) Governança da água no Brasil: uma visão interdisciplinar. São Paulo: Annablume; Fapesp; CNPq, 2009. p.111-33.

Oferta e estresse hídrico na região Metropolitana de São Paulo. Estudos Avançados, São Paulo, v.25, n.71, p.119-33, abr. 2011. Disponível em: <http://www.scielo. br/scielo.php? script $=$ sci_arttext\&pid $=S 0103-40142011000100009 \& \operatorname{lng}=$ pt\&nrm $=i$ so>.

Justiça espacial e justiça socioambiental: uma primeira aproximação. Estudos Avançados, São Paulo, v.31, n.89, p.147-65, abr. 2017. Disponível em: <http://www. scielo.br/scielo.php?script=sci_arttext\&pid=S0103-40142017000100147\&lng=pt\&n $\mathrm{rm}=\mathrm{isO}>$.

SECRETARIA DO MEIO AMBIENTE DO ESTADO DE SÃO PAULO. Recursos hídricos: histórico, gestão e planejamento. Coordenadoria de Planejamento Ambiental, Governo do Estado de São Paulo. São Paulo, 1995.

SECRETARIA DO MEIO AMBIENTE DO ESTADO DE SÃO PAULO. 1997. LEI No 9.866, DE 28 DE NOVEMBRO DE 1997. Dispõe sobre diretrizes e normas para a proteção e recuperação das bacias hidrográficas dos mananciais de interesse regional do Estado de São Paulo e dá outras providências. Governo do Estado de São Paulo, 1997.

TRIMBLE, M.; MAZZEO, N. A governança da água para adaptação e resiliência no Antropoceno. In: TORRES, P. H. C. et al. Governança e Planejamento Ambiental: Adaptação e Políticas Públicas na Macrometrópole Paulista. Rio de Janeiro: Letra Capital. 2019, p.40-5.

TUFFANI, M. Um-alerta-de-1977-para-a-crise-da-agua. Disponível em: http://mauriciotuffani.blogfolha.uol.com.br/2014/11/13/

TUNDISI, J. G.; TUNDISI, T. As múltiplas dimensões da crise hídrica. Revista USP, v.106, p.21-30, 2015.

RESUMO - Dadas a complexidade da governança da água na Região Metropolitana de São Paulo (RMSP) e a iminência de efeitos cada vez mais fortes das mudanças climáticas, o texto analisa como essas podem agravar ainda mais a situação de escassez crônica de água, seja pelo excesso de chuvas com os consequentes alagamentos e enchentes, seja com severos períodos de seca, que dificulta o abastecimento público e para os demais usos da água, incluindo os serviços ambientais e ecossistêmicos. Concluímos que é necessário aprimorar a governança da água na RMSP com participação do poder público, da população e das empresas de forma a antecipar o planejamento sistêmico necessário para que os impactos das mudanças climáticas sejam minimizados no futuro.

PALAVRAS-CHAVE: Governança da água, Região Metropolitana de São Paulo, Mudanças climáticas, Crise hídrica, Sociedade civil. 
ABSTRACT - Given the complexity of water governance in the Metropolitan region of São Paulo and the imminence of increasingly stronger effects of climate change, this article analyzes how chronic water scarcity can be further aggravated, either by excessive rainfall with consequent flooding and overflows, or by periods of severe drought, hampering both public supply and other uses of water, including environmental and ecosystemic services. We conclude that water governance must be improved in the metropolitan region of São Paulo with the participation of the government, the population and companies to anticipate the systemic planning necessary to minimize the impacts of climate change in the future.

KEYWORDS: Water governance, Metropolitan region of São Paulo, Climate changes, Water crisis, Civil society.

Pedro Roberto Jacobi é professor titular senior do Instituto de Energia e Ambiente da Universidade de São Paulo. @-prjacobi@gmail.com / https://orcid.org/0000-0001-6143-3019.

Marcos Buckeridge é professor titular, diretor do Instituto de Biociências da Universidade de São Paulo, coordenador do Programa Cidades Globais do Instituto de Estudos Avançados. @-msbuck@usp.br / https://orcid.org/0000-0002-5455-8136.

Wagner Costa Ribeiro é professor titular do Departamento de Geografia, do Programa de Pós-Graduação em Geografia Humana e do Programa de Pós-Graduação em Ciência Ambiental da Universidade de São Paulo. @ - wribeiro@usp.br / https://orcid.org/0000-0002-3485-9521.

Recebido em 25.5.2020 e aceito em 18.2.2021.

${ }^{\text {I }}$ Universidade de São Paulo, Instituto de Energia e Ambiente, São Paulo, Brasil.

II Universidade de São Paulo, Instituto de Biociências, São Paulo, Brasil.

III Universidade de São Paulo, Departamento de Geografia, Faculdade de Filosofia, Letras e Ciências Humanas, São Paulo, Brasil. 